\title{
IL- 6 and IL-10 gene polymorphisms in patients with aggressive periodontitis: effects on GCF, serum and clinic parameters
}

\section{Emine PIRIM GORGUN(a) Hulya TOKER(a) \\ Ertan Mahir KORKMAZ(b) Omer POYRAZ ${ }^{(c)}$}

\footnotetext{
(a) Cumburiyet University Faculty of Dentistry, Department of Periodontology, Sivas, Turkey.

(b) Cumhuriyet University Faculty of Sciences, Department of Molecular Biology and Genetics, Sivas, Turkey.

(c) Cumhuriyet University Faculty of Medicine, Department of Microbiology, Sivas, Turkey.
}

Declaration of Interests: The authors certify that they have no commercial or associative interest that represents a conflict of interest in connection with the manuscript.

Corresponding Author:

Emine Pirim Gorgun, DDS, PhD

E-mail: eminepirim09@hotmail.com

DOI: 10.1590/1807-3107BOR-2017.vol31.0012

Submitted: Jul 13, 2016

Accepted for publication: Nov 21, 2016

Last revision: Dec 05, 2016
Abstract: Genetic variations observed in cytokines affect periodontitis susceptibility. Theaim of thisstudy was toinvestigateinterleukin(IL)-6(-174) and IL-10(-597) gene polymorphisms in generalized aggressive periodontitis (GAgP) patients. Also, we aimed to evaluate the effects of IL-6 and IL-10 gene polymorphisms on the clinical outcomes of non-surgical periodontal therapy and cytokine levels in gingival crevicular fluid(GCF) and serum. Fifty-three patients with GAgP and 50 periodontally healthy individuals were included in this study. Clinical parameters, GCF and blood samples were collected at baseline and at 6-week. Non-surgical periodontal therapy was performed in patients with GAgP. Gene analysis were determined by PCR-RFLP(polymerase chain reaction-restriction fragment length polymorphism) and cytokine levels were determined by enzyme-linked immunosorbent assay(ELISA).GAgP patients showed significant improvement on clinical parameters after periodontal therapy $(\mathrm{p}<0.05)$. In the GAgP group, IL-6 GG genotype and $\mathrm{G}$ allele frequency were higher than in the control group. GCF IL-6 level was also significantly lower at 6-week in the GAgP group. Higher GCF IL-10 levelswere observed in patients carrying the IL-6 GG genotype than in those carrying the GC+CC genotype at baseline. In conclusion, IL-6(-174) and IL-10(-597) gene polymorphisms were found to be associated with GAgP and genotype distribution did not affect the outcome of non-surgical periodontal therapy, while patients with IL-6(-174) GG genotype had higher levels of GCF IL-10 levels.

Keywords: Interleukin-6; Interleukin-10; Polymorphism, Genetic; Aggressive Periodontitis.

\section{Introduction}

Aggressive periodontitis (AgP) is a rapidly progressing form of periodontal disease. Specific microbial environment and modified host response play crucial roles in the development and progression of the disease. ${ }^{1}$ AgP patients display inadequate host response to increased expression of a variety of immunological and genetic risk factors. ${ }^{2}$ The genetic risk of $\mathrm{AgP}$ development has been investigated in many studies in various populations. ${ }^{3,4,5}$ 
There is a complex network of pro- and anti-inflammatory cytokines acting in the diseased periodontal tissues. ${ }^{6,7}$ Also, cytokine expressions are affected by the presence of functional gene polymorphisms. ${ }^{6}$

Interleukin (IL)-6 is a pleiotropic cytokine released by many cell types, and its secretion levels are determined by the producing cell type and the genetic background of the source cells. ${ }^{8}$ Among several kinds of cytokines, IL-6 was found to be increased in gingival crevicular fluid (GCF) and gingival tissues of patients with periodontal disease. ${ }^{9}$ A recent study reported that chronic periodontitis(CP) and generalized aggressive periodontitis (GAgP) patients had significantly higher GCF IL-6 levels in comparison with the healthy subjects. ${ }^{10}$

Single nucleotide polymorphisms(SNPs) in the promoter region of IL- 6 gene at positions $-174 \mathrm{G} / \mathrm{C}(\mathrm{rs}$ 1800795), -572C/G(rs 1800796) and -597G/A(rs 1800797) have been described. First, Trevilatto et al. reported an association between IL-6(-174) gene polymorphism and $\mathrm{CP}$ in the Caucasian race. ${ }^{11} \mathrm{After}$ that,several studies found different results regarding the relationship between IL-6(-174) gene polymorphism and periodontal disease. Some of these studies did not find any association between IL-6(-174) gene polymorphism and $\mathrm{CP}_{1}^{12,13,14,15}$ however some others found associations. ${ }^{16,17}$

Studies investigating the relationship between IL-6(-174) gene polymorphism and AgP are limited. ${ }^{3,5,18,19,20}$ Erciyas et al. ${ }^{20}$ evaluated the IL-6(-174) single nucleotide polymorphisms (SNPs) in AgP in Turkish populationand found no association. However, Nibali et al. ${ }^{5}$ reported an association between IL-6(-174)GG genotype and AgP, and another study showed an association between IL-6(-174)GC genotype and AgP. ${ }^{18}$

IL-10, an anti-inflammatory cytokine, regulates the synthesis of pro-inflammatory cytokines such as IL-1, -2, -6 and stimulates protective antibody production. ${ }^{6,21}$ IL-10 is expressed in both healthy and diseased human periodontal tissues and is reported to be reduced in patients infected with Aggregatibacter actinomycetemcomitans. ${ }^{22}$

The gene encoding IL-10 was mapped to chromosome 1q31-32. The three SNPs(-1082 G/A; -819
C/T and $-592 \mathrm{C} / \mathrm{A}$ ) from the transcriptional start site have been associated with the altered synthesis of IL-10 in response to inflammatory stimuli.. ${ }^{23}$ In the literature, data on which of the IL-10 polymorphisms or variations contributes to periodontal disease are contradictory. ${ }^{4,21,24}$ The IL-10 gene polymorphism at position $-597 \mathrm{C}$ to $\mathrm{A}$ wasnot associated with the susceptibility to $\mathrm{CP}$ or $\mathrm{AgP}^{4}$

Considering the key roles of pro-inflammatory and anti-inflammatory cytokines in periodontal disease, it was questioned whether genetic variations affecting transcription or function of these cytokines contribute to the development of GAgP. Also, few studies have investigated the potential association of carrying a gene variant with the clinical response to periodontal therapy. The present study was undertaken to test the hypothesis that gene polymorphisms may affect periodontal inflammation and treatment outcomes via pro- and anti-inflammatory cytokine levels in AGP patients. Thus, the aims of this study were separated in three parts: first,to determine IL-6(-174) and IL-10(-597) gene polymorphisms in GAgP patients and healthy controls;second, to evaluate the effect of these gene polymorphisms on outcomes of non-surgical periodontal therapy; and third to investigate the effect of genotype distributions on cytokine levels in GCF and serum.

\section{Methodology}

\section{Study population}

Fifty-five patients with GAgP and 50 periodontally and systemically healthy individuals were recruited from the Department of Periodontology at Cumhuriyet University from 2011 to 2013. The study protocol was approved by the Medical Research Ethics Committee of Cumhuriyet University according to the Helsinki declarations (2011/031), and signed informed consent was obtained from all individuals.

Individuals who were evaluated for the present study were excluded if they had conservative or prosthetic restorations at the anterior region, presence of systemic disease, history of hepatitis or HIV infection, immunosuppressive chemotherapy or current pregnancy or lactation, requirement 
for antibiotic prophylaxis, history of antibiotic therapy in the previous 3 months, chronic usage of anti-inflammatory drugs and periodontal treatment in the previous 6 months. Also, smokers were excluded from the study.

The diagnostic criteria for GAgP was defined in accordance with the classification developedby the American Academy of Periodontology. ${ }^{1}$ Patients who presented with a generalized severe periodontal destruction (probing depth $\geq 5 \mathrm{~mm}$ at least on three sites other than first molars and incisors, and radiographic evidence of advanced alveolar bone loss) were diagnosed with GAgP.

Control subjects were designated as healthy if they had full-mouth probing pocket depth (PD) $<3 \mathrm{~mm}$, gingival index scores equal to 0 , andno radiographic evidence of alveolar bone loss. These individuals were included in the study as systemically and periodontally healthy volunteers. Also, all individuals came from the same geographical area.

\section{Clinical measurements and periodontal therapy}

Before crevicular fluid collection, full-mouth clinical periodontal measurements were recorded at six sites per tooth(mesio-buccal, mid-buccal, disto-buccal, disto-lingual, mid-lingual and mesio-lingual), including plaque index(PI), ${ }^{25}$ gingival index(GI), ${ }^{25} \mathrm{PD}$ and clinical attachment level (CAL). A periodontal probe (Williams probe, Hu-Friedy, Chicago, IL, USA) was used for periodontal measurements. In all patients, individual acrylic stents were fabricated with grooves as reference points for CAL measurement. The periodontal status of each patient was determined by a single calibrated researche (E.P.G.), who had experience in clinical trials. In patients with GagP, clinical periodontal measurements were performed at baseline and at 6-week. GAgP subjects received non-surgical periodontal therapy, which consists of oral hygiene instructions, scaling and root planning. The treatment procedure was performed quadrant per quadrant under local anesthesia in four visits using specific curettes (Hu-Friedy, Chicago, IL, USA). Treatment was completed within 10 days. No antibiotics were prescribed during the treatment. All patients were treated by a single periodontist (E.P.G.).

\section{GCF and serum sampling}

GCF sampling was carried out during the same session as the clinical measurements.Only the upper anterior teeth were included in the study to facilitate the access and to reduce the risk of salivary contamination during the procedures.GCF samples were collected from a proximal site of a single-rooted tooth with moderate pocket size in GagP patients and one site in control group.The GCF samples were collected using an absorbent paper strip(Periopaper; ProFlow Inc., Amityville, NY, USA), which was placed into the sulcus/pocket until mild resistance was felt and then held there for $30 \mathrm{~s}^{26}$ The procedure was performed carefully to avoid mechanical injury. Strips with contamination of blood were excluded. All strips with GCF were immediately and individually placed into sterile Eppendorf tubes and kept at $-80^{\circ} \mathrm{C}$ until required for further analysis.

Blood samples $(5 \mathrm{ml})$ were taken from the antecubital vein of all individuals and collected in tubes.Venous blood sampleswere allowed to stand for $30 \mathrm{~min}$ before being centrifuged at $6000 \mathrm{rpm}$ for $10 \mathrm{~min}$. All samples were kept in $-80^{\circ} \mathrm{C}$ conditions until the day of analysis.

\section{Cytokine assay}

On the day of the assay, $100 \mu \mathrm{l}$ phosphate buffer solution was added to GCF samples in Eppendorf tubes. GCF samples were mixed with a vortex for $1 \mathrm{~min}$ to mix the solution. After removal of the strips, the supernatants were divided into two aliquots for the determination of each cytokine. The amounts of IL- 6 and IL-10 in the serum and GCF were determined by using ELISA kits (Invitrogen, Cambrillo,USA) according to manufacturer's instructions. After color development was stopped, the absorbance was measured using a microtiter plate-computerized reader set to a wavelength of $450 \mathrm{~nm}$. GCF cytokine levels were calculated from the standard curves and defined as picogram/site for total amount of cytokine levels. The sensitivities for IL- 6 and IL-10 ELISA's were 2 and $1 \mathrm{pg} / \mathrm{mL}$, respectively. Sites with cytokine levels below the limits of the assay's detectability were scored as 0 . 


\section{Genotype analyses}

Two $\mathrm{mL}$ of blood was taken from each individual at baseline. The blood samples were collected in sodium EDTA vacutainers and stored at $-80^{\circ} \mathrm{C}$ until genetic analysis were performed. The extraction of DNA was performed with a commercial kit(Invitrogen, Cambrillo, USA) following the manufacturer's protocol.

Each sample of DNA was analyzed for polymorphisms in the IL-6 gene at position -174, and in the IL-10 gene at position -597 with PCR-RFLP. Primer sequences are shown for each primer pair in Table 1.

DNA samples were amplified by PCR (PTC-200 termal cycler, MJ Research, Watertown, MA, USA) with specific primers for each examined polymorphism. PCR reaction mixtures $(50 \mu \mathrm{l})$ contained $50 \mu \mathrm{l}$ PCR buffer, $0.2 \mathrm{mM}$ each $\mathrm{dNTP}, 10 \mathrm{pmol}$ of each primer (forward and reverse, control and allele specific), $1.5 \mathrm{~m} \mathrm{MMgCl}$, $200 \mathrm{ng}$ of genomic DNA, 0.5U Taq DNA polymerase (Fermantes,Maryland, USA) and each internal control primer.

For IL-6(-174) G/C, the following PCR protocol was used: $94^{\circ} \mathrm{C}$ for $3 \mathrm{~min}$ (initial denaturation), $94^{\circ} \mathrm{C}$ for $30 \mathrm{~s}$ (denaturation), $62.6^{\circ} \mathrm{C}$ for $40 \mathrm{~s}$ (annealing), and $72^{\circ} \mathrm{C}$ for 40 s (extension). The total number of cycles was 35 followed by a final extension of $72^{\circ} \mathrm{C}$ for $5 \mathrm{~min}$. We used NlaIII and a cleavage protocol following the manufacturer's instructions. NlaIII cleaves a restriction site at position -174 when $\mathrm{G}$ is present, leading to fragments of 29, 176, 202, and 233 base pairs (bp) in length or 29, 111, 122, 176 and $202 \mathrm{bp}$ when $C$ is present. In heterozygote individuals $(\mathrm{A} / \mathrm{C})$, fragments have 42, 66, 232, 240 and 306 bp in length.

For IL-10 (-597)A/C, the following PCR protocol was used: $94^{\circ} \mathrm{C}$ for $3 \mathrm{~min}$ (initial denaturation), $94^{\circ} \mathrm{C}$ for $30 \mathrm{~s}$ (denaturation), $48^{\circ} \mathrm{C}$ for $40 \mathrm{~s}$ (annealing), and $72^{\circ} \mathrm{C}$ for $40 \mathrm{~s}$ (extension). The total number of cycles was 35 followed by a final extension of $72^{\circ} \mathrm{C}$ for $5 \mathrm{~min}$.
We used RsaI and a cleavage protocol following the manufacturer's instructions. RsaI cleaves a restriction site at position -597 when $\mathrm{A}$ is present, leading to fragments of $42,66,232$, and $240 \mathrm{bp}$ in length or 42 , 232, and $306 \mathrm{bp}$ when $\mathrm{C}$ is present. In heterozygote individuals fragments have (A/C), 42, 66, 232, 240 and $306 \mathrm{bp}$ in length.

The alleles were separated by $3 \%$ agarose gel electrophoresis and stained with ethidium bromide. Following electrophoresis, the PCR products were visualized under ultraviolet light.

\section{Statistical analysis}

The chi-square test was used to test for deviation of genotype frequencies from Hardy- Weinberg equilibrium and to compare the genotype distributions among individuals with GAgP and healthy controls. Odds ratios (ORs) and 95\% confidence intervals were calculated to determine the strength of the association. A p-value of $<0.05$ was considered significant.

Statistical analyses were performed using the program SPSS 15.0 (SPSS Inc., Chicago, IL, USA). Demographic data and clinical parameters were reported as means \pm standard deviation. Genotype frequencies were tabulated by direct counting and allele frequencies were calculated from the observed number of genotypes. Kolmogorov-Smirnov test was used to assess the distribution of data. Comparisons among groups were performed using the Mann-Whitney U test. In the GAgP group, differences between baseline and 6-week values were analyzed by Wilcoxon rank test. The relationships among GAgP group and gene polymorphisms were analyzed by logistic regression analysis. The power of the analysis was defined by utilizing data from a previous publication. ${ }^{21}$ The sample size was calculated under a $5 \%$ error giving a required sample size of 55 in each group, with a statistical power of $80 \%$.

Table 1. Primer sequences and reaction properties for genes.

\begin{tabular}{|c|c|c|c|}
\hline Marker & Primer Sequences & $\mathrm{t} A\left({ }^{\circ} \mathrm{C}\right)$ & $\mathrm{Bp}$ \\
\hline \multirow{2}{*}{ IL-6(-174) } & 5'-GGGCTGCGATGGAGTCAGAG-3' & \multirow{2}{*}{62,6} & \multirow{2}{*}{639} \\
\hline & 5'-TCCCTCACACAGGGCTCGAC-3' & & \\
\hline \multirow{2}{*}{ IL-10(-597) } & 5'-ATCCAAGACAACACTACTAA-3' & \multirow{2}{*}{48} & \multirow{2}{*}{412} \\
\hline & 5'-TAAATATCCTCAAAGTTCC -3' & & \\
\hline
\end{tabular}

$t A$ : Annealing temperature; bp: base pairs of amplicon size. 


\section{Results}

\section{Clinical findings}

Two of the GAgP patients did not complete the periodontal therapy and were excluded from the study. The mean age and sex distribution showed no difference between the groups $(\mathrm{p}>0.05)$ (Table 2). In theGAgP group, all clinical parameters at 6 -week were significantly lower than in baseline $(p<0.05)$ (Table 3). Also, there was no significant difference between the GAgP and healthy control groups regarding PI, GI and PD values at 6-week.

\section{Distribution of genotypes and allele frequencies}

The frequency of IL-10 genotypes in the GAgP and healthy control was found in accordance with Hardy-Weinberg equilibrium ( $p>0.05)$, whereas IL-6 genotypes showed disequilibrium $(\mathrm{p}<0.05)$.

IL-6 (-174) G/C and IL-10 (-597) A/C genotype distributions were significantly different between groups ( $\mathrm{p}=0.007, \mathrm{p}=0.006$, respectively) (Table 4 ). In the GAgP group, IL-6 GG genotype was associated with 2.1 times higher risk of GAgP compared to IL-6 GC/CC genotype, however, this risk was not statistically significant (OR:2.1, 95\%Cl: 0.96-4.64, $\mathrm{p}>0.05)$. Conversely, IL-10 AA genotype was significantly associated with 7 times higher risk of GAgP compared to IL-10 AC/CC genotype (OR:7, 95\% Cl: 1.48-33.22, $\mathrm{p}<0.05)$.

Considering allele frequencies in both groups, IL-10 A allele frequency was similar in the GAgP and healthy control $(p>0.05)$. However there was a significant difference between the study groups in IL-6 G allele frequency. The frequency of G allele was

Table 2. Demographic characteristic of study groups.

\begin{tabular}{lcc}
\hline Variable & GAgP & Healthy controls \\
\cline { 2 - 3 } & $(\mathrm{n}=53)$ & $(\mathrm{n}=50)$ \\
\hline Age (years) & & \\
$\quad$ Mean \pm SD & $29.7 \pm 6.2$ & $31.8 \pm 5.2$ \\
$\quad$ Range & $15-44$ & $23-43$ \\
Gender & & \\
Male $\mathrm{n}(\%)$ & $24(45.3)$ & $17(34)$ \\
Female $\mathrm{n}(\%)$ & $29(54.7)$ & $33(66)$ \\
\hline
\end{tabular}

GAgP: generalized aggressive periodontitis; SD: standard deviation. higher in the GAgP group compared to the healthy control group $(p<0.05)$.

\section{Cytokine levels in GCF and serum}

In GAgP group, GCF IL-6 levels were significantly decreased after periodontal treatment $(p<0.05$, Table 5). Also in GAgP group, GCF IL-6 cytokine levels at baseline and 6-week were significantly higher compared to the control group $(p<0.05)$. After periodontal treatment, serum IL-6 levels were decreased, but not significantly.

GCF and serum IL-10 levels at 6-week were higher than those of baseline, but these differences were not statistically significant in the GAgP group.

In the GAgP group, individuals were categorized according to the IL-6 and IL-10 genotype distribution, and then changes in clinical and biochemical parameters were evaluated (Table 6).Significant improvements in clinical parameters were found after non-surgical periodontal therapy in individuals with both IL-6 and IL-10 genotypes ( $p<0.05)$.

In bivariate comparisons, higher PD values were foundin patients carrying IL-6 GG genotype than the IL-6 GC+CC genotypeat baseline $(\mathrm{p}<0.05)$ and higher CAL values were observed in patients carrying the IL-6 GG genotype at 6-week $(\mathrm{p}<0.05)$.

In patients carrying IL- $6 \mathrm{GC}+\mathrm{CC}$ genotype, there was a statistically significant decrease in GCF IL-6 levels at 6-week. However, in comparisons between IL-6 genotypes, serum and GCF IL-6 levels were not significantly different at 6-week. At baseline, higher

Table 3. Clinical parameters at baseline and 6-week for study groups (mean $\pm \mathrm{SD}$ ).

\begin{tabular}{lccc}
\hline \multicolumn{2}{l}{ Parameter (mean \pm SD) } & GAgP & Healthy controls \\
\hline \multirow{2}{*}{$\mathrm{PI}$} & Baseline & $1.5 \pm 0.7^{\mathrm{b}}$ & - \\
& 6-week & $0.3 \pm 0.5^{\mathrm{a}}$ & $0.2 \pm 0.4$ \\
$\mathrm{GI}$ & Baseline & $2 \pm 0.5^{\mathrm{b}}$ & - \\
& 6-week & $0.6 \pm 0.5^{\mathrm{a}}$ & $0.1 \pm 1.3$ \\
$\mathrm{PD}$ & Baseline & $5.2 \pm 0.6^{\mathrm{b}}$ & - \\
& 6-week & $3.1 \pm 1^{\mathrm{a}}$ & $2 \pm 0.7$ \\
$\mathrm{CAL}$ & Baseline & $8.7 \pm 2.5$ & - \\
& 6-week & $6.9 \pm 2.6^{\mathrm{a}}$ & $\mathrm{NA}$ \\
\hline
\end{tabular}

${ }^{a} p<0.05$ different from baseline; ${ }^{b} p<0.05$ different from healthy controls; GAgP: generalized aggressive periodontitis; PI: plaque index; Gl: gingival index; PD: pocket depth; CAL: clinical attachment level; NA, not applicable. 
Table 4. Distribution of the IL-6 (-174) and IL-10 (-597) genotypes and allele frequencies for study groups. $n(\%)$.

\begin{tabular}{cccc}
\hline \multirow{2}{*}{ Variable } & GAgP & Healthy controls & \multirow{2}{*}{ p-value } \\
\cline { 2 - 3 } Genotypes & $n=53$ & $n=50$ & \\
IL-6(-174) & & & \\
CC & $4(7.5)$ & $16(32)$ & - \\
GC & $18(34)$ & $14(28)$ & $0.007^{*}$ \\
GG & $31(58.5)$ & $20(40)$ & - \\
IL-10(-597) & & & - \\
CC & $7(13.2)$ & $3(6)$ & - \\
AC & $34(64.2)$ & $45(90)$ & $0.006^{*}$ \\
AA & $12(22.6)$ & $2(4)$ & - \\
Allele frequencies & & & - \\
IL-6(-174) & & & $0.001^{*}$ \\
C & $26(24.5)$ & $46(46)$ & - \\
G & $80(75.5)$ & $54(54)$ & \\
IL-10(-597) & & & \\
C & $48(45.28)$ & $51(51)$ & 0.274 \\
A & $58(54.8)$ & $49(49)$ & - \\
\hline * $<$ 0.05; GAgP: generalized aggressive periodontitis. &
\end{tabular}

GCF IL-10 levels were found in patients carrying the IL-6 GG genotype than in those carrying the IL-6 GC+CC genotype $(\mathrm{p}<0.05)$.

GCF IL-6 level was a significantly decreased in patients carrying the IL-10 AC+CC genotype after periodontal treatment. Also, there was no significant differences in GCF and serum IL-10 levels after non-surgical periodontal therapy in individuals with both IL-10 genotypes $(p>0.05)$.

Finally, we evaluated whether IL-6 and IL-10 genotype distributions affect the response to non-surgical periodontal therapy. Differences in clinical parameters were analyzed according to genotype distribution and no significant difference was found (Table 7).

In GAgP patients, logistic regression analysis was used to evaluate the association of the IL-6 GG and IL-10AA genotypes with periodontal disease susceptibility, while adjusting for confounders such as age and gender. It was found that neither age nor gender had effects on genotype diversity.

\section{Discussion}

Polymorphisms in the regulatory regions of the cytokine genes may change cytokine expression.
Table 5. Gingival crevicular fluid(GCF) and serum IL-6 and IL-10 levelsat baseline and 6-week (pg/30s, mean \pm SD).

\begin{tabular}{cccc}
\hline Variable & & GAgP & Healthy controls \\
\hline GCF & & & \\
IL-6 & Baseline & $126.1 \pm 214.9^{\mathrm{b}}$ & - \\
& 6-week & $52.9 \pm 92.9^{\mathrm{a}, \mathrm{b}}$ & $21.3 \pm 52.3$ \\
IL-10 & Baseline & $5.5 \pm 10.7$ & - \\
6-week & $10.5 \pm 23.2$ & $6.9 \pm 13.3$ \\
Serum & & & \\
IL-6 & Baseline & $14.2 \pm 30.8$ & - \\
& 6-week & $8.8 \pm 22.8$ & $3.1 \pm 11.4$ \\
IL-10 & Baseline & $4.4 \pm 19.4$ & - \\
& 6-week & $6.4 \pm 24.4$ & $0.8 \pm 2.6$ \\
\hline
\end{tabular}

${ }^{a} \mathrm{p}<0.05$, different from baseline; ${ }^{b} \mathrm{p}<0.05$, different from healthy controls; GAgP: generalized aggressive periodontitis.

Therefore, the polymorphisms of cytokine genes are potentially important as genetic predictors of the disease susceptibility and clinical outcomes. ${ }^{27}$ In our study, periodontal therapy improved clinical results and decreased GCF IL-6 level, consistently with the literature. ${ }^{28}$ Also, in patients with IL-6 GC+CC and IL-10 AC+CC genotypes, GCF IL-6 level was decreased at 6-week. We showed that reduced clinical inflammation was related to lower GCF IL-6 cytokine level. Contrary to our study, Oliveira et al. ${ }^{29}$ reported that GCF IL-6 level was increased in GAgP patients after treatment, but not significantly. The authors explained this situation by affirming that IL-6 acts both as pro- and anti-inflammatory cytokine at the same time. Furthermore, similar to our results, Becerik et al..$^{10}$ demonstrated that in GAgP group, GCF IL-6 cytokine level was higher than in the control group and plasma levels of IL-1beta and IL-6 were similar among GAgP, CP and gingivitis patients, and controls. Also, in this study, serum IL-6 level decreased after non-surgical periodontal therapy, but the difference was not significant. Contrary to our findings, Shimada et al. and D'Aiuto et al. reported that serum IL-6 level was decreased after periodontal therapy. ${ }^{28,30} \mathrm{GCF}$ and serum IL-10 levels increased after periodontal therapy, but no significant difference was detected. Lappin et al. ${ }^{31}$ suggested that the numbers of inflammatory leucocytes that express the IL-10 were increased in aggressive periodontitis compared to chronic periodontitis, and thenumbers of inflammatory leucocytes that express 
IL-10 are morewidely distributed than the IL- 6 and TNF-alpha. It was demonstrated that periodontal therapy improved GCF cytokine profiles by lowering IL-1 $\beta$ and increasing IL-10 levels but the mean change in IL-10 did not differ between AgP and control groups. ${ }^{29}$ Similarly, these findings were observed in our previous study.

In the literature, there are few studies investigating the relationship between AgP and IL- 6 gene polymorphisms. ${ }^{6,20,32,33}$ Supporting our results, Nibali et al.reported that IL-6 GG genotype was associated with susceptibility to AgP.5 Similarly, ameta-analysis indicated that the IL-6(-174) G allele did not modify the risk of $\mathrm{CP}$, but increased the risk of $\mathrm{AgP}{ }^{34}$ However, similar to Erciyas et al., ${ }^{20}$ Brett et al. ${ }^{18}$ evaluated IL-6(-174) gene polymorphisms in $\mathrm{CP}, \mathrm{AgP}$ and control groups in Caucasians, and they found that association between GG genotype

Table 6. Clinical Parameters, GCF and serum cytokine levels in generalized aggressive periodontitis group distributed by IL-6 and IL-10 genotypes.

\begin{tabular}{|c|c|c|c|c|}
\hline \multirow{2}{*}{ Clinical parameters } & \multicolumn{2}{|c|}{ IL-6 (mean $\pm \mathrm{SD})$} & \multicolumn{2}{|c|}{ IL-10 (mean \pm SD) } \\
\hline & $G G(n=31)$ & $G C+C C(n=22)$ & $\mathrm{AA}(\mathrm{n}=12)$ & $A C+C C(n=41)$ \\
\hline \multicolumn{5}{|l|}{$\mathrm{Pl}$} \\
\hline Baseline & $1.6 \pm 0.7$ & $1.4 \pm 0.7$ & $1.3 \pm 0.7$ & $1.6 \pm 0.7$ \\
\hline 6-week & $0.4 \pm 0.5^{* *}$ & $0.1 \pm 0.5$ & $0.2 \pm 0.4$ & $0.3 \pm 0.5$ \\
\hline $\mathrm{p}$-value & $p=0.001^{*}$ & $p=0.001^{*}$ & $p=0.006^{*}$ & $p=0.001^{*}$ \\
\hline \multicolumn{5}{|l|}{$\mathrm{Gl}$} \\
\hline Baseline & $2 \pm 0.5$ & $2.1 \pm 0.4$ & $1.8 \pm 0.7$ & $2.1 \pm 0.4$ \\
\hline 6-week & $0.7 \pm 0.5$ & $0.5 \pm 0.5$ & $0.5 \pm 0.5$ & $0.6 \pm 0.6$ \\
\hline $\mathrm{p}$-value & $p=0.001^{*}$ & $p=0.001^{*}$ & $p=0.005^{*}$ & $p=0.001^{*}$ \\
\hline \multicolumn{5}{|l|}{$\mathrm{PD}(\mathrm{mm})$} \\
\hline Baseline & $5.4 \pm 0.6^{* *}$ & $4.9 \pm 0.7$ & $4.9 \pm 0.6$ & $5.3 \pm 0.6$ \\
\hline 6-week & $3.3 \pm 1$ & $3 \pm 0.9$ & $3 \pm 0.7$ & $3.2 \pm 1$ \\
\hline $\mathrm{p}$-value & $p=0.001^{*}$ & $p=0.001^{*}$ & $p=0.004^{*}$ & $p=0.001^{*}$ \\
\hline \multicolumn{5}{|l|}{$\mathrm{CAL}(\mathrm{mm})$} \\
\hline Baseline & $9.1 \pm 2.8$ & $8.1 \pm 2.1$ & $8.1 \pm 2.7$ & $8.9 \pm 2.5$ \\
\hline 6-week & $7.5 \pm 2.7^{* *}$ & $6.1 \pm 2.2$ & $6.1 \pm 2.5$ & $7.2 \pm 2.6$ \\
\hline $\mathrm{p}$-value & $p=0.001^{*}$ & $p=0.001^{*}$ & $p=0.003^{*}$ & $p=0.001^{*}$ \\
\hline \multicolumn{5}{|l|}{ GCF IL-6 } \\
\hline Baseline & $124.3 \pm 209.1$ & $128.6 \pm 227.8$ & $209.7 \pm 335.6$ & $101.6 \pm 162.4$ \\
\hline 6-week & $39.6 \pm 55.3$ & $71.6 \pm 128.0$ & $65.9 \pm 121.4$ & $49.1 \pm 84.3$ \\
\hline $\mathrm{p}$-value & $p=0.136$ & $p=0.017^{*}$ & $p=0.131$ & $P=0.013^{*}$ \\
\hline \multicolumn{5}{|l|}{ GCF IL-10 } \\
\hline Baseline & $8 \pm 13^{* *}$ & $2.1 \pm 4.7$ & $6.6 \pm 9.4$ & $5.2 \pm 11.1$ \\
\hline 6-week & $9 \pm 19.5$ & $12.5 \pm 28.1$ & $16.1 \pm 26.4$ & $8.8 \pm 22.3$ \\
\hline$p$-value & $p=0.291$ & $p=0.171$ & $p=0.594$ & $p=0.746$ \\
\hline \multicolumn{5}{|l|}{ SERUM IL-10 } \\
\hline Baseline & $4.5 \pm 22.5$ & $9.2 \pm 27.2$ & $7.1 \pm 24.5$ & $9.7 \pm 41.6$ \\
\hline 6-week & $0.5 \pm 3$ & $10 \pm 29.4$ & $8.3 \pm 29$ & $6.9 \pm 39$ \\
\hline$p$-value & $p=0.655$ & $p=0.500$ & $p=0.317$ & $p=0.866$ \\
\hline \multicolumn{5}{|l|}{ SERUM IL-6 } \\
\hline Baseline & $27.7 \pm 91.5$ & $38.3 \pm 116.5$ & $34.1 \pm 43.8$ & $8.4 \pm 23.5$ \\
\hline 6-week & $7.2 \pm 16.9$ & $36 \pm 116.4$ & $17.5 \pm 32.8$ & $6.2 \pm 18.7$ \\
\hline $\mathrm{p}$-value & $p=0.051$ & $p=0.893$ & $p=0.068$ & $p=0.575$ \\
\hline
\end{tabular}

${ }^{*} p<0.05$ different from baseline; ${ }^{* *} p<0.05$ different from IL-6 GC+CC; PI: plaque index; GI: gingival index; PD: pocket depth; CAL: clinical attachment level; GCF: gingival crevicular fluid. 
IL-6 and IL-10 gene polymorphisms in patients with aggressive periodontitis: effects on GCF, serum and clinic parameters

Table 7. Differences of clinical parameters in generalized aggressive periodontitis patients (at baseline and 6-week) distributed by IL-6 and IL-10 genotypes.

\begin{tabular}{lcccccc}
\hline \multirow{2}{*}{ Parameter } & \multicolumn{3}{c}{ IL-6 (mean \pm SD) } & \multicolumn{3}{c}{ IL-10 (mean \pm SD) } \\
\cline { 2 - 7 } & GG & GC + CC & p-value & AA & AC+CC & $p$-value \\
\hline PI & $1.19 \pm 0.74$ & $1.31 \pm 0.64$ & 0.58 & $1.08 \pm 0.79$ & $1.29 \pm 0.67$ & 0.40 \\
GI & $1.35 \pm 0.55$ & $1.63 \pm 0.78$ & 0.10 & $1.41 \pm 0.66$ & $1.48 \pm 0.67$ & 0.49 \\
PD $(\mathrm{mm})$ & $2.09 \pm 0.94$ & $2.0 \pm 1.06$ & 0.63 & $1.91 \pm 1.08$ & $2.09 \pm 0.96$ & 0.80 \\
CAL $(\mathrm{mm})$ & $1.64 \pm 1.01$ & $1.95 \pm 1.13$ & 0.32 & $2.0 \pm 1.27$ & $1.70 \pm 1.0$ & 0.57 \\
\hline
\end{tabular}

PI: plaque index; GI: gingival index; PD: pocket depth; CAL: clinical attachment level.

prevalence was higher in $\mathrm{CP} / \mathrm{AgP}$ patients compared to control, but no association between IL-6 GG genotype and AgP was detected. IL-6(-174)G/C and (-572)G/C polymorphisms are important regulators of transcription and have been shown to affect IL-6 production. Patients with juvenile rheumatoid arthritis carrying the GG genotype have been observed to have twice as high IL-6 serum levels as patients with the CC genotype. ${ }^{35}$ Moreover, the IL-6(-174) polymorphism was associated with increased odds of the concomitant detection of Aggregatibacter actinomycetemcomitans and P. gingivalis. ${ }^{3}$ In contrast, D'Aiuto et al. ${ }^{28}$ observed that in patients with severe periodontal disease, higher serum IL-6 levels were associated with the carriage of allele C for the IL-6(-174) polymorphism. Terry et al. ${ }^{36}$ reported that genetic polymorphism in the IL-6 promoter region influence IL-6 gene transcription by rather complex interactions determined by the haplotype. Also, in a recent report, it was suggested that detecting IL-6 haplotype-positive periodontitis patients might become helpful in identifying subjects who are prone to excessive inflammatory response. However, in this study, one SNP of IL-6 gene was assessed and we could not find any differences in GCF and serum IL- 6 levels between GG and GC+CC genotypes, but GCF IL-6 levels were decreased in patients with the IL- 6 GC+CC and IL-10 AC+CC genotypes compared with the IL-6 GG patients after periodontal treatment. These findings partially support that GG genotypes affectIL-6 production in GCF but not its serum level.

Although there are limited studies about AgP in the literature, different results for IL-10(-592) gene polymorphism were demonstrated. Racial and ethnic characteristics play a role on these results. Gonzales et al. ${ }^{4}$ searched gene polymorphism in IL-10(-592) loci in AgP and CP Caucasian patients. Contrary to our results, they found no association between IL-10 AA genotype and $\mathrm{AgP}$; similar results were found by $\mathrm{Hu}$ et al. ${ }^{23}$ in Chinese population. Likewise, A allele in position -592 is more frequent in the Chinese population than in a Caucasian subgroup. ${ }^{23}$ In a Jordanian population, the frequencies of the IL-10(-1087)A and (-592)A alleles were significantly more common in $\mathrm{CP}$ patients but there was no difference for genotype distribution between localize AgP group and controls. ${ }^{37}$ A recent large-scale replication study also suggested that only IL-10SNP(rs 61815643) was associated with Dutch and German/Austrian AgP samples. ${ }^{38}$ Claudino et al. ${ }^{39}$ studied the effect of IL-10(-592) gene polymorphism on cytokine expression in $116 \mathrm{CP}$ patients and 173 control subjects. In CP, a significantly lower IL-10 mRNA expression was verified in both CA and AA genotypes when compared to CC genotype carriers. Also, in a study that investigated the possible association between IL-10(-592) and (-1082) SNPs and periodontal disease progression in a five year period was found that patients with IL-10 haplotypes experienced around 20\% fewer $\mathrm{PD} \geq 4 \mathrm{~mm}$ compared to subjects with other genotypes. ${ }^{40}$ Based on the present findings, IL-10(-592)AA genotypes did not seem to play a role in the periodontal therapy outcomes. Conversely, GCF IL-10 levels were higher in patients carrying IL-6 GG genotype compared to those of the IL-6 GC+CC genotype. This may be explained as a results of the production of anti-inflammatory cytokine IL-10 in order to reduce inflammation and reestablish homeostasis.

Our study has some plausible limitations. The studied population was small, and therefore our findings needto be corroborated in larger samples 
and should be tested ingroups of different ethnic origins. Also, other SNP of these genes and the effect of haplotype combinations have not been estimated. A precise statement about a possible association of a genetic locus with a disease can be only made if the full haplotype information has been assessed. ${ }^{38}$

\section{Conclusion}

To the best of our knowledge, this is the first study evaluating outcomes of periodontal therapy on these gene polymorphisms in $\mathrm{AgP}$ patients in the Turkish population. IL-6(-174) and IL-10(-597)

\section{References}

1. Armitage GC. Development of a classification system for periodontal diseases and conditions. Ann Periodontol. 1999;4(1):1-6. doi:10.1902/annals.1999.4.1.1

2. Vieira AR, Albandar JM. Role of genetic factors in the pathogenesis of aggressive periodontitis. Periodontol 2000. 2014;65(1):92-106. doi:10.1111/prd.12021

3. Nibali L, Griffiths GS, Donos N, Parkar M, D'Aiuto F, Tonetti MS et al. Association between interleukin-6 promoter haplotypes and aggressive periodontitis. J Clin Periodontol. 2008;35(3):193-8. doi:10.1111/j.1600051X.2007.01188.x

4. Gonzales JR, Michel J, Diete A, Herrmann JM, Bödeker RH, Meyle J. Analysis of genetic polymorphisms at the interleukin-10 loci in aggressive and chronic periodontitis. J Clin Periodontol. 2002;29(9):816-22. doi:10.1034/j.1600051X.2002.290905.x

5. Nibali L, D'Aiuto F, Donos N, Griffiths GS, Parkar M, Tonetti MS et al. Association between periodontitis and common variants in the promoter of the interleukin- 6 gene. Cytokine. 2009;45(1):50-4. doi:10.1016/j.cyto.2008.10.016

6. Moreira PR, Costa JE, Gomez RS, Gollob KJ, Dutra WO. TNFA and IL10 gene polymorphisms are not associated with periodontitis in Brazilians. Open Dent J. 2009;3(1):184-90. doi:10.2174/1874210600903010184

7. Toker H, Poyraz O, Eren K. Effect of periodontal treatment on IL-1beta, IL-1ra, and IL-10 levels in gingival crevicular fluid in patients with aggressive periodontitis. J Clin Periodontol. 2008;35(6):507-13. doi:10.1111/j.1600-051X.2008.01213.x

8. Nikolopoulos GK, Dimou NL, Hamodrakas SJ, Bagos PG. Cytokine gene polymorphisms in periodontal disease: a meta-analysis of 53 studies including 4178 cases and 4590 controls. J Clin Periodontol. 2008;35(9):754-67. doi:10.1111/ j.1600-051X.2008.01298.x gene polymorphisms might be associated withAgP, but genotype distribution for the two cytokines did not influence periodontal treatment outcomes. However, GCF IL-10 levels were higher in the IL-6 GG genotype carriers at baseline and GCF IL-6 levels only decreased in patients with the IL-6 GC+CC and IL-10 AC+CC genotypes after periodontal treatment.

\section{Acknowledgements}

This study was supported by the Scientific Research Project Fund of Cumhuriyet University under the project number Dis-113.

9. Stefani FA, Viana MB, Dupim AC, Brito JA, Gomez RS, Costa JE et al. Expression, polymorphism and methylation pattern of interleukin-6 in periodontal tissues. Immunobiology. 2013;218(7):1012-7. doi:10.1016/j. imbio.2012.12.001

10. Becerik S, Öztürk VO, Atmaca H, Atilla G, Emingil G. Gingival crevicular fluid and plasma acute-phase cytokine levels in different periodontal diseases. J Periodontol. 2012;83(10):1304-13. doi:10.1902/jop.2012.110616

11. Trevilatto PC, Scarel-Caminaga RM, Brito Jr RB, Souza AP, Line SR. Polymorphism at position -174 of IL-6 gene is associated with susceptibility to chronic periodontitis in a Caucasian Brazilian population. J Clin Periodontol. 2003;30(5):438-42. doi:10.1034/j.1600051X.2003.20016.x

12. Holla LI, Fassmann A, Stejskalová A, Znojil V, Vanĕk J, Vacha J. Analysis of the interleukin-6 gene promoter polymorphisms in Czech patients with chronic periodontitis. J Periodontol. 2004;75(1):30-6. doi:10.1902/jop.2004.75.1.30

13. Wohlfahrt JC, Wu T, Hodges JS, Hinrichs JE, Michalowicz BS. No association between selected candidate gene polymorphisms and severe chronic periodontitis. J Periodontol. 2006;77(3):426-36. doi:10.1902/jop.2006.050058

14. Xiao LM, Yan YX, Xie CJ, Fan WH, Xuan DY, Wang $\mathrm{CX}$ et al. Association among interleukin- 6 gene polymorphism, diabetes and periodontitis in a Chinese population. Oral Dis. 2009;15(8):547-53. doi:10.1111/j.16010825.2009.01584.x

15. Fan WH, Liu DL, Xiao LM, Xie CJ, Sun SY, Zhang JC. Coronary heart disease and chronic periodontitis: is polymorphism of interleukin-6 gene the common risk factor in a Chinese population? Oral Dis. 2011;17(3):270-6. doi:10.1111/j.1601-0825.2010.01736.x 
16. Babel N, Cherepnev G, Babel D, Tropmann A, Hammer M, Volk HD et al. Analysis of tumor necrosis factor-alpha, transforming growth factor-beta, interleukin-10, IL-6, and interferon-gamma gene polymorphisms in patients with chronic periodontitis. J Periodontol. 2006;77(12):1978-83. doi:10.1902/jop.2006.050315

17. Costa AM, Guimarães MC, Souza ER, Nobrega OT, Bezerra AC. Interleukin-6 (G-174C) and tumour necrosis factor-alpha (G-308A) gene polymorphisms in geriatric patients with chronic periodontitis. Gerodontology. 2010;27(1):70-5. doi:10.1111/j.1741-2358.2009.00291.x

18. Brett PM, Zygogianni P, Griffiths GS, Tomaz M, Parkar M, D'Aiuto F, et al. Functional gene polymorphisms in aggressive and chronic periodontitis. J Dent Res. 2005;84(12):1149-53. doi:10.1177/154405910508401211

19. Moreira PR, Lima PM, Sathler KO, Imanishi SA, Costa JE, Gomes RS et al. Interleukin-6 expression and gene polymorphism are associated with severity of periodontal disease in a sample of Brazilian individuals. Clin Exp Immunol. 2007;148(1):119-26. doi:10.1111/j.1365-2249.2007.03327.x

20. Erciyas K, Pehlivan S, Sever T, Igci M, Arslan A, Orbak R. Association between TNF-alpha, TGF-beta1, IL-10, IL-6 and IFN-gamma gene polymorphisms and generalized aggressive periodontitis. Clin Invest Med. 2010;33(2):E85.

21. Sumer AP, Kara N, Keles GC, Gunes S, Koprulu H, Bagci H. Association of interleukin-10 gene polymorphisms with severe generalized chronic periodontitis. J Periodontol. 2007;78(3):493-7. doi:10.1902/jop.2007.060309

22. Hirose M, Ishihara K, Saito A, Nakagawa T, Yamada S, Okuda K. Expression of cytokines and inducible nitric oxide synthase in inflamed gingival tissue. J Periodontol. 2001;72(5):590-7. doi:10.1902/jop.2001.72.5.590

23. Hu KF, Huang KC, Ho YP, Lin YC, Ho KY, Wu YM et al. Interleukin-10 (-592 C/A) and interleukin-12B (+16974 $\mathrm{A} / \mathrm{C})$ gene polymorphisms and the interleukin-10 ATA haplotype are associated with periodontitis in a Taiwanese population. J Periodontal Res. 2009;44(3):378-85. doi:10.1111/j.1600-0765.2008.01116.x

24. Yamazaki K, Tabeta K, Nakajima T, Ohsawa Y, Ueki K, Itoh H et al. Interleukin-10 gene promoter polymorphism in Japanese patients with adult and early-onset periodontitis. J Clin Periodontol. 2001;28(9):828-32. doi:10.1034/j.1600051x.2001.028009828.x

25. Loe H. The Gingival Index, the Plaque Index and the Retention Index Systems. J Periodontol. 1967;38(6):Suppl:610-6. doi:10.1902/jop.1967.38.6.610

26. Lamster IB, Hartley LJ, Vogel RI. Development of a biochemical profile for gingival crevicular fluid. Methodological considerations and evaluation of collagen-degrading and ground substance-degrading enzyme activity during experimental gingivitis. J Periodontol. 1985;56(11 Suppl):13-21. doi:10.1902/ jop.1985.56.11s.13
27. Gu W, Du DY, Huang J, Zhang LY, Liu Q, Zhu PF et al. Identification of interleukin-6 promoter polymorphisms in the Chinese Han population and their functional significance. Crit Care Med. 2008;36(5):1437-43. doi:10.1097/ CCM.0b013e31816a0adb

28. D'Aiuto F, Parkar M, Andreou G, Suvan J, Brett PM, Ready D, et al. Periodontitis and systemic inflammation: control of the local infection is associated with a reduction in serum inflammatory markers. J Dent Res. 2004;83(2):156-60. doi:10.1177/154405910408300214

29. Oliveira APL, Faveri M, Gursky LC, Mestnik MJ, Feres M, Haffajee AD et al. Effects of periodontal therapy on GCF cytokines in generalized aggressive periodontitis subjects. J Clin Periodontol. 2012;39(3):295-302. doi: 10.1111/j.1600051X.2011.01817.x

30. Shimada Y, Komatsu Y, Ikezawa-Suzuki I, Tai H, Sugita N, Yoshie $\mathrm{H}$. The effect of periodontal treatment on serum leptin, interleukin-6, and C-reactive protein. J Periodontol. 2010;81(8):1118-23. doi:10.1902/jop.2010.090741

31. Lappin DF, MacLeod CP, Kerr A, Mitchell T, Kinane DF. Anti-inflammatory cytokine IL-10 and T cell cytokine profile in periodontitis granulation tissue. Clin Exp Immunol. 2001;123(2):294-300. doi:10.1046/j.13652249.2001.01448.x

32. Song GG, Choi SJ, Ji JD, Lee YH. Association between tumor necrosis factor- $\alpha$ promoter -308 A/G, -238 A/G, interleukin-6 -174 G/C and -572 G/C polymorphisms and periodontal disease: a meta-analysis. Mol Biol Rep. 2013;40(8):5191-203. doi:10.1007/s11033-013-2621-4

33. Nibali L, Pelekos G, D’Aiuto F, Chaudhary N, Habeeb R, Ready D et al. Influence of IL-6 haplotypes on clinical and inflammatory response in aggressive periodontitis. Clin Oral Investig. 2013;17(4):1235-42. doi:10.1007/s00784-0120804-3

34. Shao MY, Huang P, Cheng R, Hu T. Interleukin-6 polymorphisms modify the risk of periodontitis: a systematic review and meta-analysis. J Zhejiang Univ Sci B. 2009;10(12):920-7. doi:10.1631/jzus.B0920279

35. Fishman D, Faulds G, Jeffery R, Mohamed-Ali V, Yudkin JS, Humphries $S$, et al. The effect of novel polymorphisms in the interleukin-6 (IL-6) gene on IL-6 transcription and plasma IL-6 levels, and an association with systemic-onset juvenile chronic arthritis. J Clin Invest. 1998;102(7):1369-76. doi:10.1172/JCI2629

36. Terry CF, Loukaci V, Green FR. Cooperative influence of genetic polymorphisms on interleukin 6 transcriptional regulation. J Biol Chem. 2000;275(24):18138-44. doi:10.1074/ jbc.M000379200

37. Jaradat SM, Ababneh KT, Jaradat SA, Abbadi MS, Taha AH, Karasneh JA, et al. Association of interleukin-10 gene promoter polymorphisms with chronic and aggressive periodontitis. Oral Dis. 2012;18(3):271-9. doi:10.1111/j.16010825.2011.01872.x 
38. Schaefer AS, Bochenek G, Manke T, Nothnagel M, Graetz $\mathrm{C}$, Thien A et al. Validation of reported genetic risk factors for periodontitis in a large-scale replication study. J Clin Periodontol. 2013;40(6):563-72. doi:10.1111/jcpe.12092

39. Claudino M, Trombone AP, Cardoso CR, Ferreira SB, Jr., Martins Jr. W, Assis GF et al. The broad effects of the functional IL-10 promoter-592 polymorphism: modulation of IL-10, TIMP-3, and OPG expression and their association with periodontal disease outcome. J Leukoc Biol. 2008;84(6):1565-73. doi:10.1189/jlb.0308184

40. Cullinan MP, Westerman B, Hamlet SM, Palmer JE, Faddy MJ, Seymour GJ et al. Progression of periodontal disease and interleukin-10 gene polymorphism. J Periodontal Res. 2008;43(3):328-33. doi:10.1111/j.1600-0765.2007.01034.x 